\title{
A tale of two songs: Singapore versus Hong Kong
}

\author{
Andy Kirkpatrick and Andrew Moody
}

\section{Introduction by Jill and Charles Hadfield (series editors)}

The text for this 'Text messages' is two 'YouTube' videos from what has become known as 'The Battle of the Songs', based on the relatively light-hearted, but nevertheless keen rivalry between Singapore and Hong Kong.

The two cities share a colonial history similar in some respects, but crucially different in others. Hong Kong was ceded to the British in three stages: Hong Kong Island in 1842, Kowloon, on the mainland, some twenty years later and the New Territories, encroaching further into the Chinese mainland, on a 99 year lease expiring in 1997. Singapore has a longer colonial history, beginning in 1819 when Sir Stanford Raffles established a British port and trading station on the island. Both colonies then followed roughly parallel paths, becoming important East - West trading centres during the $19^{\text {th }}$ and early $20^{\text {th }}$ centuries, both occupied by the Japanese in WW 2, both experiencing a huge growth in the manufacturing sector during the fifties and then becoming powerful commercial and financial centres for Asia. However their postcolonial histories are somewhat different: Singapore went through a process of democratic reform in the late forties and fifties, achieving a form of self government in 1959 and independence in 1963, via a merger with the Federation of Malaya. Civil unrest led to the establishment of an independent democratic republic in 1965. Colonial rule in Hong Kong, in contrast, ended relatively recently. The return of not only the New Territories, but the whole of Hong Kong to the People's Republic of China was agreed in 1984 and took place at the expiry of the lease in 1997. Hong Kong, unlike Singapore, is not an independent democracy, but a Special 
Administrative Region (SAR) of China.

The two songs compare the cities' different legacies in many ways with references to history and attitudes to past history, culture, conservation, language, political systems and freedom of speech. Both cities have written important chapters in the history of language contact between Chinese and English, but nevertheless demonstrate that differences that have developed between the two cities, and are celebrated by them.

Our commentators are Andy Kirkpatrick, Chair Professor of English as an International Language at the Hong Kong Institute of Education and Andrew Moody, Associate Professor and Coordinator of the MA Programme, from the Department of English, University of Macau.

\section{Texts}

The texts, 'Singapore Is A Better Place Than Hong Kong Is', written and performed by Eskewme and 'In Hong Kong Our Hearts Are Strong', written and performed by Wokstarz, are too long to be reproduced in full here, (and the written texts cannot do justice to the performed songs). However citations of the most relevant passages will be made throughout the article. The song can be viewed in full on YouTube (Eskewme 2008 and Wokstarz 2008).

\section{Language notes}

Singapore is a better place than Hong Kong is

We got more art and culture, all they got is biz

We so stylo, they just vile-o

We speak Singlish, awmost English-lah

Singapore is a smarter place than Hong Kong is

We keep more of our history than Hong Kong did

We so good tase, they jus' gone case

We speak Singlish, awmost English-lah

Can or not? 
Okay-lah!

Readers of this series will recognise in the above extract from the Singaporean song some of the distinctive linguistic features of Singaporean English from Anthea Fraser Gupta's commentary in an earlier Text Messages (Hadfield, Hadfield and Gupta 2007). Several words are spelt to capture the sounds of Singapore English, such as awmost (line 4), and tase (line 8). Other examples from later verses include:

I doe no, Cantonese izzit? (line 22).

Why you lookat me lidat? (line 28)

ESKEW ME . We very stylo milo one awreddy okay. (line 40)

There is also a distinctive Singaporean flavour to the vocabulary, with examples of the creative adaptation of standard English lexis to give expressions such as stylo milo and the term Singlish itself. Borrowings from Malay are also evident in later verses:

We so WHAM BAM

They so ayam (lines 26-27)

We pick leaders

Alamak - but not much choice! (lines 36-37)

Where ayam means 'sour' and alamak is a mild swear word.

Use of local particles is also characteristic here. The song is peppered with the informal/colloquial particle lah, as in 'Singlish, awmost English-lah' and 'Okay-lah'. Other particles in later verses are the past tense particle $l a$ and the expressive particle wa:

Our shophouses- wa! So pretty (line 14)

Distinctive grammatical patterns are also evident where the linking verb to be is deleted: ' we so stylo', 'They jus' gone case'. But, as pointed out by Gupta, this is an optional rule and BE appears here in other contexts, especially in the more formal register, for example in the title and opening line, 'Singapore is a better place than 
Hong Kong is'. The frequent use of 'izzit' as a non-variant tag-question form is also distinctive, although the use of non-variant tag forms is common in many varieties of English.

However, while linguistic features of Singapore English (Singlish, as it is called within the song) are used plentifully in the Singapore song, few features of Hong Kong English are present within the Hong Kong song:

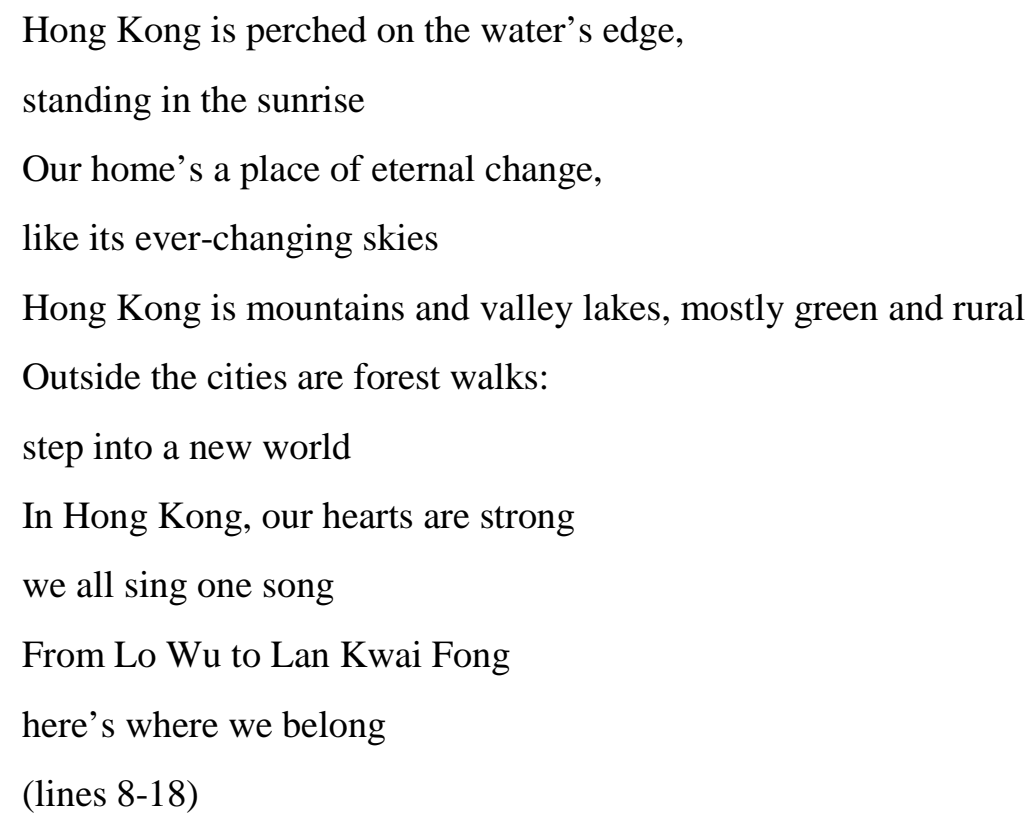

In comparing the Hong Kong song with the Singaporean one, what is most noticeable is the lack of any explicitly distinctive linguistic features of Hong Kong English used in the song. The spelling, vocabulary and grammar all conform to the British standard. The only explicit Hong Kong referents are to the place names $L o W u$, the border town with China, and Lan Kwai Fong, an area of bars and restaurants on Hong Kong Island.

There has been a long-standing debate about whether Hong Kong English represents a distinctive variety (Luke and Richards, 1982, Bolton 2000, 2003). However, the total lack of distinctive features of Hong Kong English in this song is somewhat unexpected given the number of scholars who have described features such as local lexis (Benson 2003) and creative writing (Vittachi 2003). One particularly distinctive feature of Hong Kong English that is missing within the Hong Kong song is code switching. The presence of Cantonese-English code switching in the speech and 
writing of Hong Kong speakers when they are communicating with each other is wellattested and is frequently used in popular media like newspapers and advertisements (Li 2000, 2003). Perhaps surprisingly, therefore, no code switching occurs in this song. In fact, apart from place names, there are no Chinese words here at all. Indeed, the only Chinese lexis in either of the two songs occurs in the Singaporean song, kwai-lan (line 53), a Hokkien term used to describe someone who is 'malicious or an irritant'.

\section{Commentary}

The Singaporean song is unmistakably Singaporean in its use of language. There is also a feeling of self-confidence in the use of this distinctive language, 'Singlish', coupled with humour and wit. A switch between styles is also noticeable. For example, the following text is not sung, but appears as printed text in the YouTube video, and is written in a more formal register than the rest of the song:

Okay, so the choice at newsstands is a bit limited

But the choice at the hotel buffets is not

Please discard your chewing gum, durians and independent way of thinking on your way in

(lines 42-44)

It also demonstrates an ability to self-satirize, which contrasts amusingly with the braggadocio of the rest of the song. We suggest that the song itself and its linguistic features illustrate a linguistic creativity that is both sophisticated and self-confident.

In contrast, the only example of lexical creativity or bilingual language play in Hong Kong's reply is the name of the performer Wokstarz (wok 'a convex frying pan used in Chinese cooking' in place of the more conventional rock stars.)

One explanation for this lack of code-switching and bilingual creativity is that the song-writers have taken the deliberate choice to use a form of English that is as close to an international standard as possible, a choice that may have been motivated by a desire to present Hong Kong people as more cultured, sophisticated and serious than 
the Singaporeans. One might argue that it demonstrates a linguistic sensitivity in understanding that code switching might not be understood in an international domain. However, the informal nature of the domain and topic could also signal a lack of self-confidence in the use of a local variety of Hong Kong English. The Singaporean song has a certain self-mocking tone that both explicitly pokes fun at Singapore systems and implicitly uses local forms of English to poke fun at Singapore English and its speakers. This tone is completely absent in the Hong Kong song. Instead, the Hong Kong song asserts that, unlike Singapore, 'we are free to laugh at anything' and that 'our comedians have gags' (line 34-35). The freedom to parody and laugh at Hong Kong English forms - or any other aspect of Hong Kong life - however, is not expressed in the song's text.

However, while there may appear to be no explicitly distinctive linguistic features of Hong Kong English in the song, it does display a distinctive rhetorical style that contrasts dramatically with the Singapore song. The song resonates with Chineseness. The first verse of the song, with its references to 'sunrise', 'the water's edge', 'valley lakes' and 'forest walks', is a lyrical equivalent of looking at a typical Chinese landscape or shan-shui (mountain-water) painting. It evokes a Chinese scene. The chorus, with its emphasis on a united people standing as one, looks as though it may be derived from the Olympic slogan 'One World, One Dream', but also calls to mind old Chinese Communist Party political propaganda paintings where the workers and peasants stand side by side with heads turned upwards looking towards the promise of a bright dawn. For example, the line of the refrain 'our hearts are strong' curiously uses plural 'hearts' (with the grammatically correct 'are') instead of reading 'In Hong Kong, our heart is strong'. What is suggested is that unification derives from individuals all striving toward the same goal, and this sentiment is very similar to that expressed by the Chinese term tong bao 'from the same womb', a term used by Chinese of different political persuasions and nationalities to refer to each other. The diversity of Hong Kong is also represented in the refrain's 'from Lo Wu to Lan Kwai Fong'. The distance between these two locations is as much metaphorical as it is geographical. Lo Wu represents the gateway into the Mainland, while Lan Kwai Fong symbolises the centre of Hong Kong's international community and cosmopolitan lifestyle.

The next verse suggests that Hong Kong and its people have weathered tougher times 
than Singapore and are thus made of somewhat sterner stuff:

Once refugees or just wanderers

now our home is Hong Kong

We are survivors so come what may:

history has made us strong

(lines19-22)

Hong Kong is the mature elder brother who will guide Singapore to adulthood from its current rather childish adolescent phase, perhaps exemplified in Hong Kong eyes by its use of 'Singlish, awmost English-lah':

Small Singapore is our little bro:

rivalries do blow up

We'll help him learn all the things we know:

we will help him grow up

(lines 23-26)

We should point out, however, that the sung lyric of line 26, 'we will help him grow up', is quite different from the one actually printed, which is 'though he makes us throw up'! If this printed lyric is treated as a mistaken lyric (as we suspect it is), however, the actual text is ironic. The Hong Kong song descends into cliché and stereotypical Chinese tropes, and removes any trace of local linguistic features from the text. Likewise, the Hong Kong song condescends to call Singapore 'our little bro' (line 23). However, the stereotypical motifs and rhetorical structure of the Hong Kong song can hardly be called 'mature' in comparison to the Singapore song.

Another Chinese rhetorical trope evident in the song is balance, or parallelism. This is common in many texts, but is particularly valued in the Chinese rhetorical tradition (Kirkpatrick 2005) and most frequently exemplified in couplets that adorn either side of doorways and mantels in Chinese temples and homes. This use of balance and parallelism is exemplified in lines 40-41:

Hong Kong, Hong Kong, it's east, it's west, it's old, it's young

Though once it was so tragic but now it's really magic, it's home, it's home 
Although these examples of rhetorical style borrowed from Chinese are not distinctive characteristics of Hong Kong English and could be found in various other Englishes, their presence within this song - especially when viewed as a response to the Singapore song — is marked as the only features that appear to borrowed from Hong Kong English norms. The song concludes with the chorus reiterating Hong Kong's sense of unity, 'we all sing one song'.

\section{Conclusion}

In conclusion, we argue that, while the Hong Kong song displays none of the explicitly distinctive linguistic features of a nativised variety of English, preferring instead to use a more formal register and language features that largely correspond to exonormative standards, its use of rhetorical tropes and its style imbue it with an intensely Chinese flavour. The rather prim seriousness — almost sanctimony — of the Hong Kong song is heightened by the near constant presence of two schoolgirls in the video clip. They are shown engaged in almost stereotypically innocent past-times such as playing playground pat-a-cake. This provides a striking contrast with the somewhat raunchy performance of the Singaporean singer. Similarly the adherence to Chinese conventions contrasts with the iconoclastic sense of play, creativity and capacity for self-satire of the Singaporean song.

While it would be foolish to make too much of this based on two songs, the use of Chinese rhetorical styles could indicate that Hong Kong is coming to see itself — and, importantly, presenting itself — more and more as a Chinese city, and is thus less likely to be in the process of creating a new and separate identity through a nativised variety of English in the way that Singapore has done. Rather, the Hong Kong identity revealed within this brief battle of two songs represents a move more towards seeking an identity within the Chinese sphere, and this is reflected in the use of Chinese rhetorical tropes and style. It would not be surprising to see Hong Kong moving closer to the Mainland. After all, the British ceded control more than a decade ago and Hong Kong's future is obviously inexorably tied to China, of which it is now a Special Administrative Region (SAR) under the ‘One Country Two Systems’ model of governance. Perhaps Hong Kong is becoming more comfortable with a Chinese identity, while Singapore is developing a unique Singaporean identity? 


\section{References}

Benson, P. 2003. 'Hong Kong words: variation and context' in Bolton (ed.) 2003: 161-170.

Bolton, K. 2000. 'The sociolinguistics of Hong Kong and the space for Hong Kong English'. World Englishes 19(3): 265-286.

Bolton, K. (ed.) 2003. Hong Kong English: Autonomy and creativity. Hong Kong: Hong Kong University Press.

Eskewme 2008. ‘Singapore vs Hong Kong'. YouTube, up-loaded 10 July 2008. < http://www.youtube.com/watch?v=VpjNgIwyrbE > .

Hadfield, J, C. Hadfield and A.F. Gupta 2007. 'Text Messages: Travels with Auntie’. ELT Journal 61/1: 63-68

Kirkpatrick, A. 2005. 'China's first systematic account of rhetoric: an introduction to Chen Kui’s (陈騤) Wen Ze (文则)’. Rhetorica 23/2: 103-152

Li, D.C.S. 2000. 'Cantonese-English code-switching research in Hong Kong: a Y2K review'. World Englishes 19/3: 305-322.

Li, D.C.S. 2003 'Cantonese-English code switching research in Hong Kong: a survey of recent research’ in Bolton (ed.) 2003: 79-99

Luke, K.K. and J.C. Richards 1982. ‘English in Hong Kong: status and functions’. English World-wide 3/1: 47-64.

Vittachi, N. 2003 ‘From Yinglish to sado-mastication’ in Bolton (ed.) 2003:207-218.

Wokstarz 2008. 'Re: Singapore vs Hong Kong’. YouTube, up-loaded 20 July 2008. < http://www.youtube.com/watch?v=oxrwro_YcgE > .

\section{The authors}

Andy Kirkpatrick is Chair Professor and Head of the English Department at the Hong Kong Institute of Education. Immediately prior to that, he was Professor of Language Education at Curtin University in Perth, Australia, where he worked for 11 years. In addition to Australia and Hong Kong, he has taught in the fields of Applied Linguistics and Language Teacher Education in Burma, China, Singapore and the UK. His research interests include contrastive Chinese-English rhetoric and writing, and the development of 'multilingual' varieties of English. He is currently editing the forthcoming Handbook of World Englishes to be published by Routledge in 2010 and 
working on a monograph for Hong Kong University Press 'English as a Lingua Franca in ASEAN: Roles, Features and the Multilingual Model of Language Teaching'. His 'World Englishes: implications for international communication and English Language Teaching' was published by Cambridge University Press in 2007.

Andrew Moody is an Associate Professor of English in the English Department at the University of Macau, where he teaches Sociolinguistics at both the undergraduate and graduate levels. He has taught at Universities in Beijing, China and Japan before coming to Macau and holds a PhD (University of Kansas) in English Language and Literature. His research interests include the development of varieties of world Englishes and the role of English in popular culture, especially within Asia. His articles have appeared in American Speech, World Englishes, Asian Englishes and English Today and currently editing with Jaimie Shinhee Lee a collection of essays for Hong Kong University Press entitled English in Asian Pop Culture. Currently he is involved in a long-term research project examining the language shift in Macau. 